\title{
Effect of -202 A/C IGFBP-3 polymorphisms on growth responses in children with idiopathic short stature
}

\author{
Hye Ree Kang, MD, \\ II Tae Hwang, MD, PhD, \\ Seung Yang, MD, PhD
}

Department of Pediatrics, Kangdong Sacred Heart Hospital, Seoul, Korea
Received: 29 May, 2019

Revised: 28 July, 2019

Accepted: 16 September, 2019

Address for correspondence:

Seung Yang, MD, PhD

Department of Pediatrics, Kangdong Sacred Heart Hospital, 150 Seonganro, Gangdong-gu, Seoul 05355, Korea

Tel: +82-2-2224-2251

Fax: +82-2-482-8334

E-mail: jxisfriend@gmail.com https://orcid.org/0000-0002-33806962
Purpose: This study evaluated the $-202 \mathrm{~A} / \mathrm{C}$ insulin-like growth factor binding protein 3 (IGFBP-3) promoter polymorphism as a predictor of serum IGFBP-3 concentration and growth velocity after recombinant growth hormone (rhGH) therapy in patients with idiopathic short stature (ISS).

Methods: Genotyping and serial measurement of clinical parameters were performed in 69 children with a confirmed diagnosis of ISS. Restriction fragment length polymorphism analysis was performed to determine the genotype at the -202 IGFBP-3 locus. Serum insulin-like growth factor 1 (IGF-1) and IGFBP-3 levels were measured at baseline and after 1 year of rhGH treatment, as were height standard deviation score and growth velocity.

Results: The -202 A/C IGFBP-3 genotype comprised 69.6\% AA, 24.6\% AC, and 5.8\% CC. One year of treatment did not produce a meaningful difference in IGF-1 or IGFBP-3 levels between children in the AA group and those with at least one copy of the $C$ allele ( $\mathrm{AC} / \mathrm{CC}$ group). Comparing the 2 groups after one year also revealed no significant difference in growth velocity ( $\Delta$ Height: $9.061 \pm 1.612 \mathrm{~cm} / \mathrm{yr}$ in the AA group, $9.421 \pm 1.864$ in the AC/CC group, $P=0.419$ ).

Conclusion: rhGH treatment was effective and there were no significant differences in IGF-1, IGFBP-3, or growth velocity according to genotype. Thus, -202 IGFBP-3 genotype may not be a major factor affecting individual growth responses in Korean children with ISS.

Keywords: Insulin-like growth factor binding protein 3, Polymorphism, Idiopathic short stature, Growth hormone

\section{Introduction}

Short stature is defined as a condition in which height is less than the corresponding mean for a given age, sex, and population group by more than 2 standard deviation scores (SDSs). ${ }^{1}$ There are multiple causes of short stature, such as nutritional, systemic, endocrine, or chromosomal abnormalities. Idiopathic short stature (ISS) is diagnosed when all other known causes of growth failure have been excluded, and when patients present with a normal or increased level of serum growth hormone $(\mathrm{GH})$ during $\mathrm{GH}$ stimulation testing. ${ }^{1-3)}$

Use of recombinant human GH (rhGH) was approved in 2003 by the U.S. Food and Drug Administration to improve the final height of patients with ISS. ${ }^{4}$ One study described increases in first-year growth velocity, height SDS, serum insulin-like growth factor I (IGF1), and IGF-binding protein-3 (IGFBP-3) levels after rhGH treatment of children with ISS. ${ }^{2,5}$ ) However, another study reported that despite the overall effectiveness of rhGH therapy, interindividual variability could occur, including a lack of response. ${ }^{6}$ )

IGF-1 is an important mediator of the effects of GH. IGFBP-3 and acid labile subunits bind to IGF-1 in the bloodstream and transport IGF to target tissues. Therefore, serum IGFBP-3 level is clinically important in relation to growth. The IGFBP-3 gene is located in the 
7p14-p12.11 chromosomal region. The gene's promoter region contains several single nucleotide polymorphisms (SNPs). The -202 A/C SNP located 202 bp upstream of the transcription start site consists of an A to C nucleotide change. This SNP is associated with serum IGFBP-3 concentrations in healthy adults. Serum IGFBP-3 levels are highest in patients with the AA genotype, followed by the AC and CC genotypes. ${ }^{7-14)}$

An association of the A allele in the IGFBP-3 promoter region with increased IGFBP-3 concentration and growth velocity after $\mathrm{GH}$ therapy has been observed in prepubertal children with GH deficiency $(\mathrm{GHD})^{15)}$ and Turner syndrome. ${ }^{16)}$ However, IGFBP-3 polymorphisms in pediatric ISS patients have not been investigated. The present study assessed the role of $-202 \mathrm{~A} / \mathrm{C}$ IGFBP-3 promoter polymorphism in ISS patients treated using rhGH.

\section{Materials and methods}

\section{Subjects}

Children 4 to 16 years of age who underwent a GH stimulation test at Kangdong Sacred Heart Hospital from May 2014 to August 2016 were enrolled in the study. ISS diagnosis was based on a height more than 2 standard deviations (SDs) below the mean for the relevant age and sex groups; one or more incidences of peak GH levels $\geq 7 \mathrm{ng} / \mathrm{mL}$ on $\mathrm{GH}$ simulation test with 2 different stimulants (clonidine, arginine, or levodopa); no GH treatment within at least the previous 6 months; and normal thyroid hormone levels. Exclusion criteria included diagnoses of dysmorphic syndrome, skeletal dysplasia, small for gestational age (SGA), anemia, chronic disease, hypopituitarism, GHD, Cushing syndrome, or chromosomal abnormalities, or a history of use of a medication known to affect GH.

Eighty-one patients were diagnosed with ISS; of these, the -202 A/C IGFBP-3 promoter genotype was confirmed in 69 patients. Growth responses were analyzed over a 1-year period. A left-hand radiograph (including the wrist) was acquired to determine skeletal maturity, and bone age (BA) was determined by an experienced pediatric endocrinologist using the Greulich and Pyle atlas. BA was recorded in years. rhGH was administered subcutaneously at a mean dose of $0.79 \pm 0.15 \mathrm{IU} /$ $\mathrm{kg} / \mathrm{wk}$ for $11.9 \pm 2.7$ months (median, 12.0 months). The dose was adjusted at each visit according to changes in weight.

The study protocol was approved by the Institutional Review Board (IRB) of Kangdong Sacred Heart Hospital, Seoul, Korea (IRB No. 2013-02-023). All patients or their parents provided written informed consent before participating.

\section{Hormone assays}

Serum IGF-1 and IGFBP-3 levels were measured by chemiluminescent immunoassay (IMMULITE 2000; Siemens Medical Solutions Diagnostics, Los Angeles, CA, USA) at the start of therapy and 1 year later. Measured values were substituted by
SDS for age and sex in accordance with the serum levels for Koreans of the appropriate age and gender. ${ }^{17}$

\section{Molecular studies}

Genomic DNA was extracted from blood samples from the participants. The IGFBP-3 -202 SNP was amplified from the DNA samples by polymerase chain reaction using primers 5'-CCA CGA GGT ACA CAC GAA TG-3' (forward) and 5'-AGC CGC AGT GCT CGC ATC TGG-3' (reverse), as previously described. ${ }^{18)}$ Genotyping of the IGFBP-3 locus was accomplished by restriction fragment length polymorphism analysis, as previously described. ${ }^{19)}$ Identification of the $-202 \mathrm{~A} /$ C IGFBP-3 allele was based on expected sizes of $242 \mathrm{bp}$ and 162 bp for AA; 288 bp and 162 bp for CC; and 288, 242, and 162 bp for AC.

\section{Statistical analyses}

Qualitative values are expressed as frequencies and percentages. Quantitative values are expressed as mean \pm standard deviation. Children with ISS were divided into tertile groups according to first-year growth velocity SDS ( $\triangle$ Height SDS/ $\mathrm{yr}$ ), and the frequency of the A and $\mathrm{C}$ alleles in each group was compared using the chi-square test. Serum IGF-1 and IGFBP-3 concentrations and the IGF-1/IGFBP-3 ratio according to -202 IGFBP-3 promoter genotype were compared using an independent sample t-test. Analysis of the therapeutic effects of $\mathrm{GH}$ was performed using paired $t$-tests. A $P$-value of $<0.05$ was considered statistically significant. All statistical analyses were performed using IBM SPSS Statistics ver. 24.0 (IBM Co., Armonk, NY, USA).

\section{Results}

\section{Patient characteristics and genotype distribution}

Sixty-nine children with ISS (37 boys and 32 girls) were evaluated. Baseline characteristics prior to treatment included chronological age (CA) of $8.5 \pm 2.9$ years, BA of $6.7 \pm 3.1$ years, short stature (height SDS, $-2.213 \pm 0.556$ ), body mass index (BMI) SDS of $-3.149 \pm 1.398$, and midparental height SDS of $-0.688 \pm 0.752$.

The -202 A/C IGFBP-3 SNP comprised 3 genotypes: $69.6 \%$ AA $(n=48), 24.6 \%$ AC $(n=17)$, and 5.8\% CC $(n=4)$. Since so few patients were homozygous for the $\mathrm{C}$ allele, we classified the patients into two -202 A/C IGFBP-3 genotype groups: the AA group and the AC/CC group. These 2 groups were statistically similar with regard to baseline chronological and BA, height SDS, BMI SDS, and mean rhGH dose (Table 1). 
Table 1. Baseline auxological and endocrinological findings for 69 children with ISS grouped according to the -202 A/C IGFBP-3 genotype $(n=69)$

\begin{tabular}{|c|c|c|c|}
\hline Variable & AA & $A C+C C$ & $P$-value \\
\hline No. of patients (\%) & $48(69.6)$ & $21(30.4)$ & \\
\hline Sex, male:female & $25: 23$ & $12: 9$ & 0.698 \\
\hline CA (yr) & $8.6 \pm 3.0$ & $8.2 \pm 2.8$ & 0.571 \\
\hline $\mathrm{BA}(\mathrm{yr})$ & $6.9 \pm 3.3$ & $6.1 \pm 2.6$ & 0.327 \\
\hline Bone age delay* (yr) & $1.7 \pm 1.1$ & $2.1 \pm 1.1$ & 0.196 \\
\hline Height SDS & $-2.140 \pm 0.613$ & $-2.380 \pm 3.506$ & 0.098 \\
\hline BMI SDS & $-3.271 \pm 1.460$ & $-2.870 \pm 1.234$ & 0.276 \\
\hline IGF-1 (ng/mL) & $162 \pm 80$ & $144 \pm 68$ & 0.376 \\
\hline IGF-1 SDS & $-0.784 \pm 0.781$ & $-0.858 \pm 0.673$ & 0.707 \\
\hline IGFBP-3 (ng/mL) & $4,115 \pm 1,001$ & $3,562 \pm 879$ & 0.032 \\
\hline IGFBP-3 SDS & $2,234 \pm 1,197$ & $1,609 \pm 1,682$ & 0.084 \\
\hline IGF-1/IGFBP-3 ratio & $0.038 \pm 0.011$ & $0.040 \pm 0.015$ & 0.404 \\
\hline rhGH dose (IU/kg/wk) & $0.79 \pm 0.14$ & $0.79 \pm 0.17$ & 0.993 \\
\hline
\end{tabular}

Values are presented as mean \pm standard deviation unless otherwise indicated.

ISS, idiopathic short stature; IGFBP-3, insulin-like growth factor binding protein 3; CA, chronologic age; BA, bone age; SDS, standard deviation score; BMI, body mass index; IGF-1, insulin-like growth factor 1; rhGH, recombinant human growth hormone. *Bone age delay=CA-BA.

\section{Serum IGF-1 and IGFBP-3 SDS levels}

The 1-year growth response was evaluated in relation to -202 A/C IGFBP-3 genotype in 69 ISS patients. Patients in the AA allele group presented with higher IGF-1 and IGF-1 SDS levels than those in the $\mathrm{AC} / \mathrm{CC}$ group before and after 1 year of treatment; however, this difference was not significant (Tables 1, 2).

IGFBP- 3 concentration was significantly higher in the AA group than in the AC/CC group $(4,115 \pm 1,001$ vs. $3,562 \pm 879$, respectively; $P=0.032$ ) before starting treatment. There was tendency toward higher IGFBP-3 SDS in the AA group, but this was not statistically significant $(2,234 \pm 1,197$ vs. $1,609 \pm 1,682$, $P=0.084$ ) (Table 1).

In addition, levels of IGFBP-3 and IGFBP-3 SDS in the AA group after 1 year of treatment were higher than those in the $\mathrm{AC} / \mathrm{CC}$ group; however, this difference was not significant (Table 2). There were no significant differences in the IGF-1/ IGFBP- 3 ratio between the AA group and the AC/CC group before and after 1 year of treatment (Tables 1,2).

\section{Growth velocity after one year of GH therapy}

Height SDS was significantly increased after one year of GH therapy in all -202 A/C IGFBP-3 genotype groups compared to baseline height SDS $(P<0.001)$. IGF-1 and IGFBP-3 SDS levels in both groups also increased significantly after 1 year of treatment compared to baseline levels $(P<0.001)$. The mean height gain during the year of treatment was $9.2 \pm 1.7 \mathrm{~cm} / \mathrm{yr}$ among 69 children with ISS
Table 2. First year growth response to rhGH treatment in 69 children with ISS, grouped according to the -202 A/C IGFBP-3 genotype $(n=69)$

\begin{tabular}{|c|c|c|c|}
\hline Variable & AA & $A C+C C$ & $P$-value \\
\hline CA (yr) & $9.7 \pm 3.0$ & $9.2 \pm 2.8$ & 0.580 \\
\hline $\mathrm{BA}(\mathrm{yr})$ & $8.3 \pm 3.1$ & $7.6 \pm 2.5$ & 0.318 \\
\hline Bone age delay ${ }^{*}(y r)$ & $1.3 \pm 1.0$ & $1.7 \pm 1.1$ & 0.190 \\
\hline$\triangle B A / \triangle C A$ & $1.33 \pm .083$ & $1.34 \pm 0.64$ & 0.949 \\
\hline Height SDS & $-1.517 \pm 0.588$ & $-1.631 \pm 0.525$ & 0.447 \\
\hline BMI SDS & $-3.067 \pm 1.444$ & $-2.808 \pm 1.492$ & 0.499 \\
\hline IGF-1 (ng/mL) & $284 \pm 135$ & $233 \pm 95$ & 0.077 \\
\hline IGF-1 SDS & $0.299 \pm 1.293$ & $-0.124 \pm 0.802$ & 0.172 \\
\hline IGFBP-3 (ng/mL) & $4,887 \pm 1,066$ & $4,401 \pm 949$ & 0.077 \\
\hline IGFBP-3 SDS & $3,074 \pm 1,534$ & $2,539 \pm 1,709$ & 0.202 \\
\hline IGF-1/IGFBP-3 ratio & $0.057 \pm 0.021$ & $0.052 \pm 0.144$ & 0.285 \\
\hline rhGH dose (IU/kg/wk) & $0.76 \pm 0.11$ & $0.82 \pm 0.13$ & 0.057 \\
\hline First year growth velocity ${ }^{\dagger}$ & $9.061 \pm 1.612$ & $9.421 \pm 1.864$ & 0.419 \\
\hline
\end{tabular}

$(\mathrm{cm} / \mathrm{yr})$

Values are presented as mean \pm standard deviation.

rhGH, recombinant human growth hormone; ISS, idiopathic short stature; IGFBP-3, insulin-like growth factor binding protein 3; CA, chronologic age; BA, bone age; SDS, standard deviation score; BMI, body mass index; IGF-1, insulin-like growth factor 1 .

"Bone age delay $=C A-B A .{ }^{\dagger}$ First year growth velocity $=\Delta$ Height/yr.

BA also increased after one year of GH treatment. Mean BA was delayed beyond 1 year compared to CA before and after 1 year of treatment; however, no notable difference was observed between the AA group and the AC/CC group (Tables $1,2)$. The change in $B A$ was more advanced than the change in $\mathrm{CA}$, although this difference was not significant between the 2 groups ( $\triangle \mathrm{BA} / \triangle \mathrm{CA}: 1.33 \pm 0.83$ vs. $1.34 \pm 0.64, P=0.949$ ) (Table 2 ). While first-year growth velocity was higher in the group with 1 or 2 copies of the $\mathrm{C}$ allele than in the homozygous $\mathrm{A}$ allele group, this was not significantly different $(\Delta$ Height/year: $9.061 \pm 1.612$ vs. $9.421 \pm 1.864, P=0.419$ ) (Table 2). Similar results were observed for first-year growth velocities with SDS adjusted for sex and age $(\Delta$ Height $S D S / y r: 0.639 \pm 0.349$ vs. $0.762 \pm 0.363$, $P=0.188$ ) (Fig. 1A). There were also no significant differences in $\Delta$ IGF-1 SDS (1.083 \pm 1.347 vs. $0.734 \pm 0.716, P=0.269), \Delta \mathrm{IGFBP}-3$ SDS $(0.840 \pm 1.481$ vs. $0.929 \pm 1.535, P=0.820)$, or $\Delta \mathrm{IGF}-1 /$ $\triangle \mathrm{IGFBP}-3(1.556 \pm 0.525$ vs. $1.388 \pm 0.444, P=0.204)$ between the 2 groups (Fig. 1B, C).

\section{Allelic frequency in relation to first-year growth velocity SDS}

According to the change in height SDS from baseline to one year of rhGH treatment, all 69 patients were divided into 3 groups ( $n=23$ per group): poor, moderate, and good. The firstyear growth velocity SDS ( $\triangle$ Height SDS/yr) of patients in the poor group was less than 0.543 , that of the moderate group was 0.543 to 0.812 , and that of the good group was more than 0.812 .

A allele frequency was $84.8 \%$ in the poor group, $82.6 \%$ in the moderate group, and $78.3 \%$ in the good group. A allele 

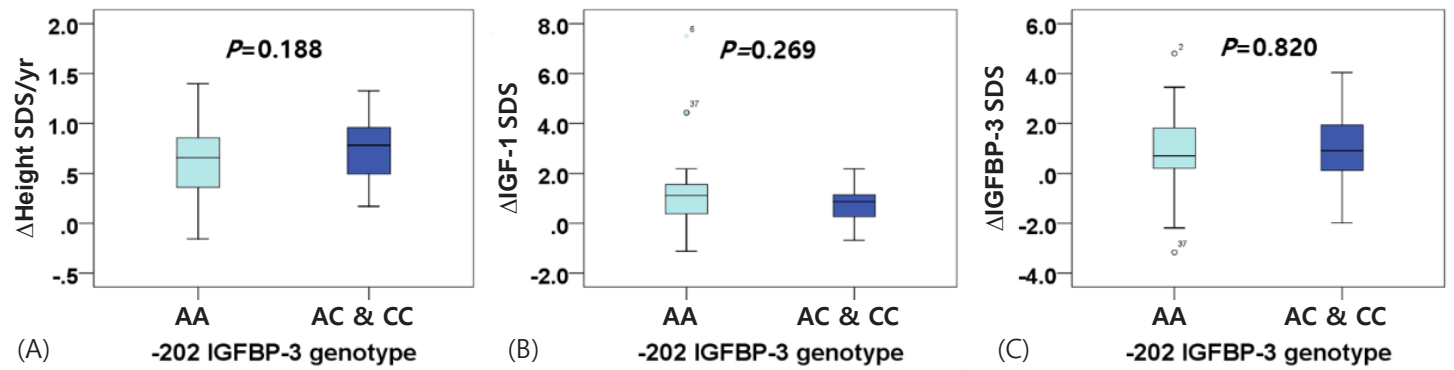

Fig. 1. Influence of -202 A/C IGFBP-3 genotype on first-year growth velocity SDS, IGF-1 SDS levels, and IGFBP-3 SDS levels in 69 children with ISS, before and after treatment. (A) $\triangle$ Height SDS/yr, (B) $\triangle I G F-1$ SDS, (C) $\triangle I G F B P-3$ SDS. IGFBP-3, insulin-like growth factor binding protein 3; SDS, standard deviation score; ISS, idiopathic short stature; IGF-1, insulin-like growth factor 1.

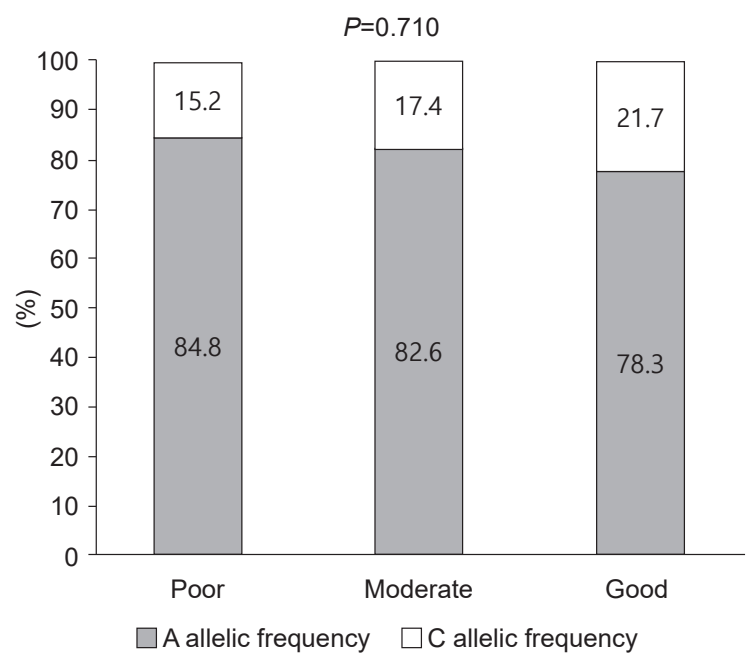

Fig. 2. Allelic frequency of -202 A/C IGFBP-3 polymorphisms after one year of rhGH treatment in children with ISS. The 69 patients were divided into 3 groups ( $n=23$ per group) according to first-year growth velocity SDS ( $\triangle$ Height SDS/ yr): poor, <0.543; 0.543 to 0.812 , moderate; and $>0.812$, good. IGFBP-3, insulinlike growth factor binding protein 3; rhGH, recombinant growth hormone; ISS, idiopathic short stature; SDS, standard deviation score.

frequency decreased with increasing first-year growth velocity. The frequency of the $\mathrm{C}$ allele was $15.2 \%$ in the poor group, $17.4 \%$ in the moderate group, and $21.7 \%$ in the good group. C allele frequency increased as growth rate increased, but this was not statistically significant $(P=0.710)$ (Fig. 2).

\section{Discussion}

In our study, the distribution of the -202 A/C IGFBP-3 genotype was $69.6 \% \mathrm{AA}, 24.6 \% \mathrm{AC}$, and $5.8 \% \mathrm{CC}$ (4 of 69 ). The A allele frequency was $82 \%$ and the $\mathrm{C}$ allele frequency was $18 \%$. These results echo those from a previous study performed in Korean children. ${ }^{19)}$ Other prior studies described frequencies of the -202 A/C IGFBP-3 genotype in a European population as $16 \%-23 \% \mathrm{AA}, 53 \%-64 \% \mathrm{AC}$, and $20 \%-24 \% \mathrm{CC}^{20,21)}$ with frequencies of $56 \%-63 \% \mathrm{AA}, 32 \%-39 \% \mathrm{AC}$, and $5 \% \mathrm{CC}$ reported in East Asians, ${ }^{22,23)}$ similar to this study. These results
Table 3. Genotypic frequency of the -202 A/C IGFBP-3 polymorphisms in prior studies

\begin{tabular}{|c|c|c|c|c|c|}
\hline \multirow[t]{2}{*}{ Study } & \multirow[t]{2}{*}{ Subject } & \multirow[t]{2}{*}{ No. } & \multicolumn{3}{|c|}{$\begin{array}{c}\text {-202 A/C IGFBP-3 } \\
\text { genotype (\%) }\end{array}$} \\
\hline & & & $\mathrm{AA}$ & $A C$ & CC \\
\hline Wang et al. ${ }^{22)}$ & Japanese population & 272 & 56 & 39 & 5 \\
\hline Xiang et al. $^{23)}$ & Chinese population & 212 & 63 & 32 & 5 \\
\hline Miletta et al. ${ }^{20)}$ & Swiss population & 211 & 16 & 64 & 20 \\
\hline Hendriks et al. ${ }^{21)}$ & Dutch population & 206 & 23 & 53 & 24 \\
\hline
\end{tabular}

IGFBP-3, insulin-like growth factor binding protein 3.

imply genotypic variation according to ethnicity or race, with the $\mathrm{C}$ allele being relatively prevalent in Europeans (Table 3). In a multiethnic population study, subjects were divided into quartile groups according to adult height. The mean IGFBP-3 level was higher in the $\mathrm{A}$ allele group than in the $\mathrm{C}$ allele group, and $\mathrm{C}$ allele frequency was higher in the taller group than in the shorter group.") One study reported catch-up growth after GH therapy in SGA, in which the target population was shown to have lower mean IGFBP-3 SDS level and higher mean height SDS in the $\mathrm{C}$ allele than in the $\mathrm{A}$ allele. ${ }^{24)}$ If serum IGFBP- 3 levels are lower for the $\mathrm{C}$ allele than the $\mathrm{A}$ allele, serum IGF-1 binding is presumed to be low and free IGF-1 levels are presumed to be elevated. Therefore, the $\mathrm{C}$ allele presumably contributes to greater stature in Europeans compared to East Asians, which conforms with social norms.

GH is used to treat children with ISS (2003), GHD (1985), chronic renal insufficiency (1993), SGA (2001), and syndromic diseases such as Turner syndrome (1997), Prader-Willi syndrome (2000), and Noonan syndrome (2007). ${ }^{4.5)}$ Children with the same cause of short stature who are treated with a similar dose of GH exhibit significant interindividual variability in short- and long-term growth responses. ${ }^{15,16,25,26)}$ Previous prediction models of the response to GH based on clinical parameters explain approximately $50 \%$ of this variability. Thus, recent interest has focused on the potential influence of genetic variation within the GH-IGF-1 axis. ${ }^{27-29)}$ IGFBP-3 is the major protein carrier for circulating IGF-1 and IGF-2, and also modulates IGF activity. ${ }^{30)}$ Deal et al. ${ }^{7)}$ described a SNP in the IGFBP- 3 promoter, which featured an $\mathrm{A}$ to $\mathrm{C}$ nucleotide change 202 bp upstream of the transcription start site $(-202 \mathrm{~A} / \mathrm{C})$ 
near elements believed to control basal promoter activity. The authors also reported that healthy adults with an AA genotype displayed higher mean IGFBP-3 levels than levels in those with AC or CC genotypes. Comparable results have been reported in children with $\mathrm{GHD}^{15)}$ and Turner syndrome. ${ }^{16)}$ To the best of our knowledge, no prior studies have reported an association between serum IGFBP-3 levels and growth velocity according to the -202 A/C IGFBP-3 polymorphism in children with ISS.

In the present study, there were no significant differences in first-year growth responses to GH therapy between the AA group and the AC/CC group. Furthermore, there was no correlation between genotypes and serum IGFBP-3 levels. Serum IGFBP-3 level was slightly higher and first-year growth velocity was lower in the AA group than in the AC/CC group. There appears to be a difference in $\mathrm{C}$ allele frequency depending on ethnicity and race, and estimated serum-free IGF-1 levels were relatively elevated for the $\mathrm{C}$ allele group, which may explain the greater growth. Serum-free IGF-1 level was estimated based on the IGF-1/IGFBP-3 ratio. However, IGF-1/IGFBP-3 ratio was similar among genotypes. In a previous study, serum IGFBP-3 levels differed significantly depending on genotype; however, the IGF-1/IGFBP-3 ratio was not different. ${ }^{14,19)}$ These findings suggest that serum IGF-1 concentrations reflect neither systemically nor locally produced IGF- 1 , and that variation at the -202 IGFBP-3 locus does not directly affect serum IGF-1 or free IGF-1 levels.

GH therapy resulted in a significant increase in first-year growth velocity and mean first-year growth velocity SDS compared to baseline. These results are consistent with prior studies. In one study, first-year growth velocity $(10.68 \pm 1.95$ $\mathrm{cm} / \mathrm{yr})$ and $\Delta$ Height SDS $(0.63 \pm 0.16)$ increased significantly after 6 months of GH therapy in Korean children with ISS. ${ }^{5)}$ Other studies reported an increased velocity of $8-9 \mathrm{~cm} / \mathrm{yr}$ in the first year of GH treatment compared with $4-5 \mathrm{~cm} / \mathrm{yr}$ before treatment. ${ }^{31,32)}$ The BMI SDS of children with ISS was less than $2 \mathrm{SD}$ in our study. Wudy et al. ${ }^{33)}$ reported that decreased appetite and lower BMI in ISS patients contribute to their short stature. In addition, BMI reportedly modulates the IGF-1 response to $\mathrm{GH}$ administration in children with ISS, suggesting that GH sensitivity may be affected by nutritional status. ${ }^{34}$

Our study has some limitations. First, -202 A/C IGFBP-3 genotypes could not be divided into 3 groups because of the low frequency of the CC genotype in the Korean population. Second, the sample size was relatively small. The CC genotype represented $25 \%$ (18 of 71) of the population in the GHD ${ }^{15}$ ) study and 35\% (39 of 112) in the Turner syndrome study. ${ }^{16}$ IGFBP-3 levels and growth velocities between these 2 studies statistically differed depending on genotype. Therefore, increasing the sample size or selecting an ethnicity with a high frequency of the CC genotype as the target group may help in obtaining effective results. Third, serum IGF-1, and IGFBP-3 levels do not accurately reflect concentrations in local tissues, especially growth plates. Despite these limitations, this study is noteworthy as it is the first attempt to evaluate the impact of -202 A/C IGFBP-3 polymorphisms in children with ISS.
Further studies that include a larger number of ISS patients are warranted.

In conclusion, we evaluated the possible association of IGF-1, IGFBP-3, and growth velocity with -202 A/C IGFBP-3 promoter polymorphisms in children with ISS. GH treatment was effective and there were no significant differences in IGF1, IGFBP-3, or growth velocity according to genotype. Thus, -202 IGFBP-3 genotype may not be a major factor affecting interindividual growth response in Korean children with ISS. Since the frequency of the $\mathrm{C}$ allele varies by ethnicity and race, further studies in different populations should be conducted to definitively determine the role of this polymorphism.

\section{Conflict of interest}

No potential conflict of interest relevant to this article was reported.

\section{Acknowledgments}

This study was financially supported by a research grant from the Investigator-Initiated Trials program of Dong-A ST Co., LTD. Opinions expressed in this paper are those of the authors and do not represent those of Dong-A ST Co., LTD. The authors would also like to thank Dong-A ST Co., LTD for supporting this research.

\section{References}

1. Wit JM, Clayton PE, Rogol AD, Savage MO, Saenger PH, Cohen P. Idiopathic short stature: definition, epidemiology, and diagnostic evaluation. Growth Horm IGF Res 2008;18:89-110.

2. Kim HS, Yang SW, Yoo HW, Suh BK, Ko CW, Chung WY, et al. Efficacy of short-term growth hormone treatment in prepubertal children with idiopathic short stature. Yonsei Med J 2014;55:53-60.

3. Ranke MB. Towards a consensus on the definition of idiopathic short stature. Horm Res 1996;45 Suppl 2:64-6.

4. Ayyar VS. History of growth hormone therapy. Indian J Endocrinol Metab 2011;15 Suppl 3:S162-5.

5. Kim J, Suh BK, Ko CW, Lee KH, Shin CH, Hwang JS, et al. Recombinant growth hormone therapy for prepubertal children with idiopathic short stature in Korea: a phase III randomized trial. J Endocrinol Invest 2018;41:475-83.

6. Grimberg A, DiVall SA, Polychronakos C, Allen DB, Cohen LE, Quintos JB, et al. Guidelines for growth hormone and insulin-like growth factor-i treatment in children and adolescents: growth hormone deficiency, idiopathic short stature, and primary insulin-like growth factor-I deficiency. Horm Res Paediatr 2016;86:361-97.

7. Deal C, Ma J, Wilkin F, Paquette J, Rozen F, Ge B, Hudson T, et al. Novel promoter polymorphism in insulin-like growth 
factor-binding protein-3: correlation with serum levels and interaction with known regulators. J Clin Endocrinol Metab 2001;86:1274-80.

8. Al-Zahrani A, Sandhu MS, Luben RN, Thompson D, Baynes C, Pooley KA, et al. IGF1 and IGFBP3 tagging polymorphisms are associated with circulating levels of IGF1, IGFBP3 and risk of breast cancer. Hum Mol Genet 2006;15:1-10.

9. Cheng I, DeLellis Henderson K, Haiman CA, Kolonel LN, Henderson BE, Freedman ML, et al. Genetic determinants of circulating insulin-like growth factor (IGF)-I, IGF binding protein (BP)-1, and IGFBP-3 levels in a multiethnic population. J Clin Endocrinol Metab 2007;92:3660-6.

10. Jernström H, Deal C, Wilkin F, Chu W, Tao Y, Majeed $\mathrm{N}$, et al. Genetic and nongenetic factors associated with variation of plasma levels of insulin-like growth factor-I and insulin-like growth factor-binding protein-3 in healthy premenopausal women. Cancer Epidemiol Biomarkers Prev 2001;10:377-84.

11. Morimoto LM, Newcomb PA, White E, Bigler J, Potter JD. Variation in plasma insulin-like growth factor- 1 and insulin-like growth factor binding protein-3: genetic factors. Cancer Epidemiol Biomarkers Prev 2005;14:1394401.

12. Ren Z, Cai Q, Shu XO, Cai H, Li C, Yu H, et al. Genetic polymorphisms in the IGFBP3 gene: association with breast cancer risk and blood IGFBP-3 protein levels among Chinese women. Cancer Epidemiol Biomarkers Prev 2004; 13:1290-5.

13. Schernhammer ES, Hankinson SE, Hunter DJ, Blouin MJ, Pollak MN. Polymorphic variation at the -202 locus in IGFBP3: Influence on serum levels of insulin-like growth factors, interaction with plasma retinol and vitamin D and breast cancer risk. Int J Cancer 2003; 107:60-4.

14. Slattery ML, Baumgartner KB, Byers T, Guiliano A, Sweeney C, Herrick J, et al. Genetic, anthropometric, and lifestyle factors associated with IGF-1 and IGFBP-3 levels in Hispanic and non-Hispanic white women. Cancer Causes Control 2005; 16:1147-57.

15. Costalonga EF, Antonini SR, Guerra-Junior G, Mendonca BB, Arnhold IJ, Jorge AA. The -202 A allele of insulinlike growth factor binding protein-3 (IGFBP3) promoter polymorphism is associated with higher IGFBP-3 serum levels and better growth response to growth hormone treatment in patients with severe growth hormone deficiency. J Clin Endocrinol Metab 2009;94:588-95.

16. Braz AF, Costalonga EF, Montenegro LR, Trarbach EB, Antonini SR, Malaquias AC, et al. The interactive effect of GHR-exon 3 and -202 A/C IGFBP3 polymorphisms on rhGH responsiveness and treatment outcomes in patients with Turner syndrome. J Clin Endocrinol Metab 2012;97:E671-7.

17. Hyun SE, Lee BC, Suh BK, Chung SC, Ko CW, Kim HS, et al. Reference values for serum levels of insulin-like growth factor-I and insulin-like growth factor binding protein-3 in Korean children and adolescents. Clin Biochem 2012;45:16-21.

18. Schildkraut JM, Demark-Wahnefried W, Wenham RM, Grubber J, Jeffreys AS, Grambow SC, et al. IGF1 (CA)19 repeat and IGFBP3 -202 A/C genotypes and the risk of prostate cancer in Black and White men. Cancer Epidemiol Biomarkers Prev 2005; 14:403-8.

19. Yi MJ, Park TY, Hwang IT, Yang S. Influence of The -202 A/ $\mathrm{C}$ insulin-like growth factor-binding protein-3 promoter polymorphism on individual variation in height in Korean girls. Ann Pediatr Endocrinol Metab 2017;22:36-42.

20. Miletta MC, Scheidegger UA, Giordano M, Bozzola M, Pagani S, Bona G, et al. Association of the (CA)n repeat polymorphism of insulin-like growth factor-I and -202 A/C IGF-binding protein-3 promoter polymorphism with adult height in patients with severe growth hormone deficiency. Clin Endocrinol (Oxf) 2012;76:683-90.

21. Hendriks AE, Brown MR, Boot AM, Oostra BA, de Jong $\mathrm{FH}$, Drop SL, et al. Common polymorphisms in the GH/ IGF-1 axis contribute to growth in extremely tall subjects. Growth Horm IGF Res 2011;21:318-24.

22. Wang L, Habuchi T, Tsuchiya N, Mitsumori K, Ohyama C, Sato $\mathrm{K}$, et al. Insulin-like growth factor-binding protein-3 gene $-202 \mathrm{~A} / \mathrm{C}$ polymorphism is correlated with advanced disease status in prostate cancer. Cancer Res 2003;63:440711.

23. Xiang H, Liu L, Chu GD, Wei S, Liu JP, Xu YH, et al. Association between two functional polymorphisms of insulinlike growth factor binding protein 3 and colorectal cancer risk in a Chinese population. J Toxicol Environ Health A 2009;72:706-11.

24. van der Kaay DC, Hendriks AE, Ester WA, Leunissen RW, Willemsen RH, de Kort SW, et al. Genetic and epigenetic variability in the gene for IGFBP-3 (IGFBP3): correlation with serum IGFBP-3 levels and growth in short children born small for gestational age. Growth Horm IGF Res 2009;19:198-205.

25. Ranke MB, Lindberg A, Chatelain P, Wilton P, Cutfield W, Albertsson-Wikland $\mathrm{K}$, et al. Derivation and validation of a mathematical model for predicting the response to exogenous recombinant human growth hormone $(\mathrm{GH})$ in prepubertal children with idiopathic GH deficiency. KIGS International Board. Kabi Pharmacia International Growth Study. J Clin Endocrinol Metab 1999;84:1174-83.

26. de Ridder MA, Stijnen T, Hokken-Koelega AC. Prediction of adult height in growth-hormone-treated children with growth hormone deficiency. J Clin Endocrinol Metab 2007;92:925-31.

27. Jorge AA, Marchisotti FG, Montenegro LR, Carvalho LR, Mendonca BB, Arnhold IJ. Growth hormone (GH) pharmacogenetics: influence of GH receptor exon 3 retention or deletion on first-year growth response and final height in patients with severe GH deficiency. J Clin Endocrinol Metab 2006;91:1076-80.

28. Goddard AD, Covello R, Luoh SM, Clackson T, Attie KM, 
Gesundheit N, et al. Mutations of the growth hormone receptor in children with idiopathic short stature. The Growth Hormone Insensitivity Study Group. N Engl J Med 1995;333:1093-8.

29. Meyer S, Ipek M, Keth A, Minnemann T, von Mach MA, Weise A, et al. Short stature and decreased insulin-like growth factor I (IGF-I)/growth hormone (GH)-ratio in an adult $\mathrm{GH}$-deficient patient pointing to additional partial $\mathrm{GH}$ insensitivity due to a R179C mutation of the growth hormone receptor. Growth Horm IGF Res 2007;17:307-14.

30. Ferry RJ Jr, Cerri RW, Cohen P. Insulin-like growth factor binding proteins: new proteins, new functions. Horm Res 1999;51:53-67.

31. Hopwood NJ, Hintz RL, Gertner JM, Attie KM, Johanson AJ, Baptista J, et al. Growth response of children with non- growth-hormone deficiency and marked short stature during three years of growth hormone therapy. J Pediatr 1993;123:215-22.

32. Wit JM, Reiter EO, Ross JL, Saenger PH, Savage MO, Rogol $\mathrm{AD}$, et al. Idiopathic short stature: management and growth hormone treatment. Growth Horm IGF Res 2008; 18:11135.

33. Wudy SA, Hagemann S, Dempfle A, Ringler G, Blum WF, Berthold LD, et al. Children with idiopathic short stature are poor eaters and have decreased body mass index. Pediatrics 2005; 116:e52-7.

34. Roman R, Iniguez G, Lammoglia JJ, Avila A, Salazar T, Cassorla F. The IGF-I response to growth hormone is related to body mass index in short children with normal weight. Horm Res 2009;72:10-4. 